\title{
MUNICIPAL OPEN DATA PORTALS: THEIR IMPLEMENTATION IN THE FACE OF A MUNICIPALITY'S POLITICAL AND TERRITORIAL REALITY
}

\author{
J. Diaz ${ }^{1}$, S. Breux ${ }^{2}$ \\ ${ }^{1}$ Université du Québec à Montréal, Montreal, Canada (diaz.jeremy@courrier.uqam.ca) \\ ${ }^{2}$ Institut National de Recherche Scientifique, Montreal, Canada (sandra.breux@ucs.inrs.ca)
}

KEYWORDS: Open Data, Open Data Portal, Smart City, Reusers, Montreal

\begin{abstract}
Municipal open data portals have been criticized for their inability to fulfill the promises of transparency, citizen participation and economic development that are supposed to accompany data release. Based on an analysis of certain aspects of the City of Montréal's open data portal and interviews with reusers of these data, we show that the limitations observed stem - at least in part - from an absence of consideration of the municipality's political and territorial reality. Three facts contribute to this absence: 1) the Montreal open data portal was designed as a public service; 2) it was created upstream, and not based on the identification of possible needs of the population or the territory; and 3) the relevance of the published datasets raises questions with respect to the promises made. These elements invite us to better link open data portals to objectives and needs that are first and foremost local, while inserting them into a broader framework for achieving the initial democratic and economic promises.
\end{abstract}

\section{INTRODUCTION}

The desire of some cities to become "smart" often goes hand in hand with the release of the data they possess: "This convergence of smart cities and open data initiatives is fast unfolding across a number of cities like New York, Amsterdam, Helsinki, Chicago, Barcelona, Quebec City, Rio, Dublin, Nairobi and Manchester, albeit at different paces and scales" (Ojo, Curry and Zeleti, 2015, p. 2326). The number of municipal open data portals (ODPs) has thus increased in recent years (Danneels, Viaene and Van den Bergh, 2017; Ruijer et al., 2020), suggesting that these data might have untapped potential to benefit individuals, groups and public administrations alike (Open Knowledge Foundation, n.d.). The reality, however, seems to reflect a more mixed picture: there is a discrepancy between the objectives pursued by these portals, their uses and their actual impacts (Zuiderwijk, Shinde and Janssen, 2019; Neves, de Castro Neto and Aparicio, 2020).

Indeed, the evaluation of municipal ODPs shows several limitations. These are technical or informational, such as the lower quality of the data, their formats and links with other data providers (Danneels, Viaene and Van den Bergh, 2017; Vetrò et al., 2016). Other analyses highlight pitfalls related to institutional culture, inadequate legislation, low participation of data reusers and uncertainty about the benefits to be derived from these initiatives (Jansen et al., 2012). Moreover, the open data policies that accompany these portals often tend to pursue similar goals of "transparency, participation, and economic value" (Zuiderwijk, Shinde and Janssen, 2019), while municipal competencies and means vary by context (Zhu and Freeman, 2019), explaining the diversity of successes. For some, these limitations are not surprising, as there is still some vagueness in how to respond to the demands of open government, so "[...] the public sector faces the challenges and opportunities of reform and adaptation in response to the constant stimulus of innovation in the new lexicon of 'open government'" (Magalhães Santos, 2019, p. 98)

Despite the recognition of these limits, few reflections-to our knowledge - question the political reasons for the gap between the ideals pursued by these initiatives, especially municipal ones, and their concretization. On the one hand, the nature of these ideals is rarely discussed, let alone contested, even though they are intended to guide all open data initiatives, regardless of the local context of the municipalities. On the other hand, while the reuse of data is considered to be potentially valuable, the potential added value is not - to our knowledge - analyzed from a political and territorial angle. Finally, little thought is given to the place, importance, and role that a government may have in the ecosystem that can be created by open data (Abella, Ortiz-deUrbina-Criado and De-Pablos-Heredero, 2019). Yet, to reach its full potential, local open data initiatives are supposed to function as ecosystems: the form and nature of these ecosystems, however, still remains poorly documented (Zuiderwijk, Janssen and Davis, 2014). Finally, the target audience(s) for this potential value creation do not always seem to be clearly identified (Johnson, 2019). Thus, there remains a need to reflect on the political dimension of data liberation initiatives at the municipal scale, in order to more finely grasp the potential gap that exists between the promises pursued and the initiatives implemented.

The objective of this article is to address this gap. First, we will review the ideals behind open data, the different forms of existing portals and the profile of the users of these data. Then, based on the results of the analysis of certain aspects of the City of Montréal's portal, according to the categorization of Paquienséguy and Dimitrova (2018) and based on interviews with dataset reusers (reference removed for the evaluation), we will show that the limitations encountered by the ODP stem-at least in part-from the absence of a consideration of the municipality's political and territorial reality. Three facts contribute to this absence: 1) the Montreal ODP is designed as a public service; 2) it was created upstream, and not based on the identification of possible needs of the population or the territory; and 3) the relevance of the published datasets raises questions with respect to the promises made. These elements invite us to better link ODPs to objectives and needs that are first and foremost local, while inserting them into a broader framework for achieving the initial democratic and economic promises. We conclude this reflection by proposing a research agenda that will allow us to explore the various limits identified.

\section{OPEN DATA: FROM IDEALS TO PRACTICE}

Within the literature, ODPs are generally discussed from three perspectives: the ideals pursued by open data and the values that guide portal design (Zuiderwijk et al., 2014; Danneels, Viaene

${ }^{1}$ Corresponding author 
and Van den Bergh, 2017), the profile of reusers (Zhu and Freeman, 2019) and, finally, the evaluations of these portals.

Early work did, in fact, put forward the ideals that open data represented, recalling that the concept of open data was born out of the belief that an enormous amount of information systematically collected by government should be accessible to all citizens (World Bank, 2019). Transforming government data into open data would provide important benefits: increased transparency, participation and collaboration as well as stimulating innovation and economic development. These supposed benefits have progressively become goals for governments, who have been mobilizing significant financial and human resources since the first government policies on open data emerged in 2009 (World Bank, 2013; The Economist, 2013). Within this work, there is no distinction that is made between different policy scales.

Others focus on what form open data policies can take. The initial ones followed the model of an offer: make existing data public. Such policies are not without limitations, the main one being the idea that publishing data is not enough to solicit interest. Other experiences have been more demand-driven, reacting to the demand of reusers. Danneels, Viaene and Van den Bergh (2017) propose a view turned more to the epistemologies of knowledge that underlie these platforms. Others (Lassinantti, Ståhlbröst and Runardotter, 2019) emphasize the need to create value, defined as follows: "The key objective of open government is to achieve public or citizen value, be it economic, political, social or strategic in nature or pertain to quality of life" (Wirtz, Weyerer and Rösch, 2019, p. 577).

This need to create value led to a second series of writings to determine who these ODPs were intended for. Five types of users are thus recurrent in the literature, sometimes named differently depending on the author and context: non-professional users, journalists, academia, community and business (Abella, Ortizde-Urbina-Criado and De-Pablos-Heredero, 2019). Others, in very specific contexts, have analyzed the nature of the relationships that are created between these reusers, the portal created and the municipal government (Washington, 2019). This work has identified a number of limitations that have led to the third set of writings.

While these initiatives are often in the early stages of development (Noda, Yoshida and Honda, 2019) and thus do not fulfill the original mandate, there are many limitations, such as regarding technical infrastructure, organizational culture, data storage issues, cybersecurity and governance (Shepherd et al., 2019), as mentioned in the introduction to this text. These findings have led to a series of implementation guides (Sunlight Foundation, n.d.) or theoretical frameworks. Within these writings, several remarks related to the realization of the goals of open data challenge the work of public servants.

For example, Zuiderwijk et al. (2019) point out that there is a real challenge for civil servants to concretize the objectives related to open data: "OGDI [open government data initiative] objectives are often generic, focusing on objectives like transparency, participation and economic value. This makes it difficult for practitioners to know exactly what should be done to achieve the objectives." (p.665). Others point to the magnitude of the task, particularly with regard to interoperability between different departments within a municipality and organizational culture: "The implications for public administrators responsible for implementing open data or considering its adoption include the need to adapt implementation strategies and goals to account for differences across departments, both in terms of their capacities and larger organizational purpose" (Young, 2020, online). More prosaically, but nonetheless real, Prieto, Mazon and LozanoTello (2019) assert that open data teams have limited budgets and little time to release data. Hable et al. (2019) even state that sometimes "municipalities generally perceive engagement in open data initiatives as extra work which is not predefined in task descriptions" (p. 76).

Yet some recommendations suggest an increased commitment from municipalities to achieve the goals associated with open data, be it to increase the quality of accessible public data (Sadiq and Indulska, 2017) or to overcome various organizational risks associated with these initiatives. Lobre and Lebraty (2012) identified two types of risks associated with open data management: those related to information control (e.g., low reliability of information or clumsy and erroneous interpretations of data) and those related to information security (e.g., inadvertent disclosure of data). They argue that "many of the risks are largely manageable by the organizations that will use them, provided they develop the necessary skills to do so" (p. 114). They recommend the creation of a team dedicated to these informational problems, but doubt that public organizations have the capacity to implement such measures.

In light of this, a paradox emerges regarding the role of municipalities in open data initiatives. While it was demanded by open data advocates that public authorities restrict themselves to the role of data provider and let the crowd generate and select content through the use of open data, municipalities are increasingly asked to play a leadership and stimulator role in order to overcome criticism and achieve the stated goals of these same advocates (transparency, citizen participation, innovation and economic development). The open data ideology originally revolved around driving innovation, namely by pushing for a withdrawal of public authorities. The aim was to employ the skills of a diverse crowd of individuals in the reuse of government-provided data. Ironically, however, open data initiatives today are increasingly permitting a return of government

This paradox is clearly identifiable in work adopting an ecosystem analysis of open data. Borrowed from geography, the ecosystem metaphor is used to describe a "system of people, practices, values, and technologies in a particular local environment" (Harrison, Prado and Cook, 2012, p. 906) by highlighting the various interactions and interdependencies of its components. Open data ecosystems have been analyzed from different aspects: their temporal evolutions (Heimstädt et al, 2014), their compositions (Immonen, Palviainen and Ovaska, 2014; Zuiderwijk, Janssen and Davis, 2014; Ponte, 2015; Lindman and Kuk, 2015), the role of intermediaries (Van Schalkwyk, Willmers and McNaughton, 2016), business models (Kitsios, Papachristos and Kamariotou, 2017) or legal constraints (Kassen, 2018). Among this literature, a number of researchers have described the roles and functions of actors in various ecosystems. Where some identify three main roles in an open data ecosystem, namely data providers, intermediaries (including reusers) and data consumers (Heimstädt, Saunderson and Heath, 2014), others distinguish six main roles in an open data ecosystem (data providers, service providers, application developers, application users, infrastructure and tool providers, and data brokers), subdivided into twenty-two categories (Immonen, Palviainen and Ovaska, 2014, p. 99).

Interestingly, while this work agrees on the importance of a diversity of actors and roles, particularly intermediaries within 
these ecosystems, a consensus does not emerge on the role assigned to public organizations. On the one hand, it seems to be accepted that public organizations should play a leadership role internally to make public open data accessible (Harrison, Prado and Cook, 2012). On the other hand, this leadership role within local open data ecosystems is contested. As Sébastien Martin, Slim Turki and Samuel Renault (2017) point out, "envisioning public bodies as stimulators of the ecosystem may be a paradox since they have been broadly criticized. The question is meaningful as there cannot be a leadership if the actor aiming to endorse this function is not recognized as legitimate to do so by the other stakeholders" (p. 59).

Nevertheless, it is clear that these public organizations have a de facto central position in these ecosystems because they provide their data and define the legal framework for their reuse (Van Schalkwyk, Willmers and McNaughton, 2016; Kassen, 2018). The positioning of public organizations in these ecosystems thus seems to be more of an ideological debate that goes beyond the issue of open data. As Katia Lobre and Jean-Fabrice Lebraty (2012) pointed out that "in its early days, open source experienced ideological debates identical to those currently put forward by open data actors. It is therefore highly likely that it is these debates that will disappear, and not the practice, with the development of coherent and profitable business models around open data" (p. 125).

Recent writings on this debate suggest that the realization of open data ideals has not always been fully thought through, planned and funded, and that municipalities, while responsible for this release of data, may not have everything in hand to achieve the desired goals. To document and better understand this potential gap, we use the example of the City of Montréal's ODP.

\section{METHODOLOGY}

The development of the City of Montréal's ODP is closely linked to the smart city project. The first reflections on open data began in 2011 in Montreal. The City quickly launched its first ODP, and in 2012 adopted its first open data policy (Dickner, 2017). In 2013, municipal elections brought a new team to power. The municipal administration then took action to make Montreal a smart city. The ODP is one of the administration's priorities. In 2015, the open data policy was revised. The City of Montréal advocates a default opening of its datasets, but remains attentive in practice to citizens' requests in order to meet their needs on a case-by-case basis. In November 2017, the arrival of a new political team at city hall continued the development of the portal. In 2017, the ODP was entrusted to a specific branch of the City, the Montreal Urban Innovation Lab. In 2019, the open data policy was revised to increase the quality and participation of the portal and open data. The funding of the team's activities has been ensured, finally, by the fact that Montreal won a fifty-million dollar prize at the Canadian Smart Cities Challenge.

\subsection{Main characteristics of the portal}

Our approach has been twofold. On the one hand, based on the categorization of Paquienséguy and Dimitrova (2018), we identified: 1) the guideline of the open data policy of the City of Montréal; 2) the different actors who feed the data portal; 3) the nature of the available datasets; 4) the target audiences, and 5) the nature of the consulted datasets. This first step allowed us to draw a broad portrait of the portal. Data portals are the essential tools for municipalities to open up their data. They are "ideologically permeable mediation tools" (Rouquette, 2009, p. 297) that reflect the choices of the municipal administrations that designed them as well as the network of actors who feed and use them (Paquienséguy and Dymytrova, 2018).

We also conducted interviews with reusers of the City of Montréal's portal datasets. These were conducted as part of a mandate carried out for the Urban Innovation Lab - in charge of the City of Montréal's ODP, whose objective was to profile potential reusers. The Urban Innovation Lab circulated our mandate within its network in order to recruit representatives of these categories of users whom we could interview. Our interview grid aimed to capture the type of user, the type of request, the data processing chain, the type of uses, the type of impacts, and the use value created. We conducted 19 interviews in the summer of 2020. We will not present here the content of the interviews (which is available online at Reference removed for evaluation), but rather present the insights that the interpretation of these interviews led to.

There are two limitations to our methodology. First, the analysis of the portal conducted in 2021 focused on the new version of the site, while the old version was still in effect, until December 2020, when the interviews were conducted. These interviews therefore only reflect part of the reality of the portal's reuse, just as the analysis of the portal only represents a snapshot of the portal at a given moment.

\section{RESULTS}

This section presents the results of the analysis of the Montreal ODP and its users.

The guiding principle of Montreal's ODP is to facilitate transparency by offering an access service to municipal information. According to Montreal's open data policy published in 2015, the City of Montréal intends to "specify to its administrative units their duties with respect to the opening of data and to expose to citizens their rights regarding access to this data" $(2015$, p. 3). Through this document, Montreal recognizes several benefits to open access to its data: "transparency of public administration, democratic and social life, economic development and organizational efficiency" (Ville de Montréal, 2015 , p. 5 ; our translation). It is committed to disseminating its data on the portal, consulting with citizens and data users to take their needs into account, facilitating the sharing of data internally and with citizens, and ensuring the quality of data.

In 2019, the City of Montréal's open data team commissioned the organization Datopian to optimize the use of the CKAN data management platform and revise its ODP front-end. The following table summarizes its technical characteristics.

Table 1: Technical characteristics of the Montreal ODP

\begin{tabular}{|c|c|}
\hline Address of the portal & https://donnees.montreal.ca/ \\
\hline Designer & City of Montréal \\
\hline Developer & Datopian \\
\hline $\begin{array}{c}\text { Date of conception of the } \\
\text { platform }\end{array}$ & 2019 \\
\hline $\begin{array}{c}\text { Technologies of the platform } \\
\text { (back-end) }\end{array}$ & $\begin{array}{c}\text { CKAN (administration } \\
\text { panel) + Qlik Sense (data } \\
\text { analysis and visualization) }+ \\
\text { Apache Airflow (open } \\
\text { source tool for workflow } \\
\text { orchestration) }\end{array}$ \\
\hline
\end{tabular}




\begin{tabular}{|c|c|}
\hline $\begin{array}{c}\text { Technology of the portal } \\
\text { (front-end) }\end{array}$ & $\begin{array}{c}\text { HTML, } \\
\text { Customized development of } \\
\text { the City of Montréal's } \\
\text { portal }^{2}\end{array}$ \\
\hline Data validation process & $\begin{array}{c}\text { Each administrative unit of } \\
\text { the City is a data trustee } \\
\text { (mandated to produce, } \\
\text { manage and ensure the } \\
\text { integrity of information } \\
\text { resources) + the open data } \\
\text { team + the legal department } \\
\text { of the City of Montréal (if } \\
\text { relevant). }\end{array}$ \\
\hline
\end{tabular}

During this process, the open data team expressed various needs that guided the portal's functionality for end users: ability to download data in various formats; higher number of APIs; ability to discuss with citizens; showcasing of citizen projects; contextualization of data; and visualization of data as tables or maps. According to the open data team, a next version will address the creation of a knowledge base to support open data users.

A limited network of actors is involved in feeding the content accessible on the Montreal ODP. There are two different types of actors: data providers and developers of applications based on the reuse of data provided on the portal. For the first category, we observe five actors: the City of Montréal (297 sets provided), the Société de transport de Montréal (7 sets), Bixi Montréal (2 sets), the Agence de mobilite durable (1 set) and the Bureau du Taxi de Montréal (1 set). For the second category, the portal presents 29 developed applications. The list, which is not exhaustive, includes 21 citizen applications, 5 applications developed internally by the City and 3 business applications (in the field of mobility).

As of March 2021, the portal features 12 categories of datasets: agriculture and food ( 3 sets); economy and business ( 3 sets); education and research ( 0 sets); environment, natural resources, and energy (60 sets); government and finance (95 sets); infrastructure (81 sets); law, justice, and public safety (18 sets); social policy ( 9 sets); health (6 sets); society and culture ( 21 sets); tourism (14 sets); and transportation (43 sets). However, out of the 310 accessible datasets, 90 percent of the datasets belong to the fields of mobility, environment and infrastructure and, more specifically, field data (locations, events, administrative data).

The portal's user audience is rather broad, not having been defined in a specific way and not offering content to targeted clienteles. It is aimed at all visitors without distinction as to the nature of their profiles or their needs. Our survey showed that a pool of 200 people contact the ODP every year. The users fall into the categories already identified in the literature. The analysis of 19 semi-structured interviews with volunteers who are open data users allowed to identify two types of profiles: "explorers - those who use the data for personal purposes to develop their skills and see what can be done with the data-and exploiters - those who interact with the data in order to create a product that can be monetized" (reference removed for evaluation). Nevertheless, it should be noted that all those who agreed to answer our questions have the skills to read and process or use the data or are surrounded by people who can help them. These results also captured the way in which data, its use and the function of a portal are conceived. The initiative to publish the data was perceived positively by the volunteers interviewed, which can likely be attributed to the fact that they see it as a gain both for their professional practices and for their personal projects. The ideals pursued by open data seem to have been well perceived and understood by open data reusers. However, the interviewees pointed out three limitations.

In the course of discussions with the volunteers, open data was associated with the smart city, a futuristic idea that tends to conjure promises more so than lead to actual realizations (Barbudo, 2015). First, the reusers interviewed point to the variable quality of the data and to the fact that the published databases require considerable restructuring. The observation about the data quality is, in itself, not surprising: the literature has shown that this is often the case, especially with municipal portals. In the case of the City of Montréal, this is explained in particular by the fact that open data implies interoperability between the different services. In the case of the City of Montréal, the municipal mergers of the early 2000s transformed the City into 19 boroughs, some of which have retained the boundaries of former cities and towns. This has resulted in the maintenance of cultures specific to each of the boroughs, which hinders the harmonization of practices for the development of datasets.

Second, the lack of follow-up after the creation of open data products is lamented by some users. Reusers expressed disappointment with the amount of time required for cleaning the data as well as the lack of a network for meeting people who might take an interest in the product, be it to collaborate with the creation of a product or to use it. One reuser, for example, was a city dweller who created a map that could be of interest to others, and another one was a developer who created a specific application. In other words, in addition to the release of data, there was an expectation to be interlinked. The reusers therefore expected the platform and even the municipality - through the team in charge of the platform - to be connected with people who might be interested in their creations. More specifically, an interest from the municipality seemed to be expected.

Thirdly, the nature of the data published sometimes raised questions. The interest in the data varied. Some people said that they had been looking forward to the opening of the portal with impatience, only to consult it very rarely, given the low interest in the datasets published. Others were more optimistic and pointed out that the published data will probably gain in interest. Still others questioned the prioritization of open data and how it is published. There seems to be a lack of clarity about how the platform works and how it is fed in general. To answer some of the questions about the availability of datasets, the City of Montréal has published an inventory of the datasets with accessibility levels.

Thus, the Montreal ODP is an initiative driven by the City as a means to meet the ideals pursued by open data. Although commendable, the initiative did not originate from the needs of citizens but rather from the municipality's desire to create such a portal. Moreover, the identification of the actors who feed the portal highlights the pre-eminence of the City, since only four other actors participate in this initiative, and in a much more modest way. Similarly, although many dataset are published, most of them concern four major datasets. Nor is the portal designed according to types of reusers but more for the average reuser-if there is one. Reusers report some limitations of the portal with respect to the quality of the published data, the lack of follow-up from the municipality when they want to create something and the nature of the published data. Although these

${ }^{2}$ The code has been made available for free use 
limitations echo other experiences (Máchová and Lněnička, 2016; Sadiq and Indulska, 2017; Hivon and Titah, 2017), they allow identifying that one of the problems encountered is the lack of a consideration of the political and territorial context underlying the initiative.

\section{DISCUSSION: THE IMPLEMENTATION OF MUNICIPAL OPEN DATA PORTALS IN THE FACE OF A MUNICIPALITY'S POLITICAL AND TERRITORIAL REALITY}

In general, our investigation shows that the objectives of transparency, citizen participation and economic development are only partially achieved by the City of Montréal's ODP. There is, therefore, a gap between the realization of this initiative and the promises made. There are three reasons for this. One, the ODP, driven by the City, is designed as a public service. Two, such a conception has consequences on the role that the municipality can have within this portal and its facilitation. Three, the data published sometimes appear to have little connection with the needs of the population or the territory, questioning their usefulness. These characteristics point to the lack of consideration of the political and territorial reality underlying the municipal ODP initiative, which explains-at least in part-the limitations encountered. The following discussion will focus on these various elements.

\subsection{An access service to public information without direct participation}

The ODP is designed as a public service (Johnson, 2019). In this sense, by publishing different datasets, the municipality fulfills its role as a service provider. While this role matches one part of the functions of a municipality, conceived as one service among others, the ODP generates several limitations that are obstacles to meeting the needs of the user population and achieving the ideals pursued. Defined as a service, the ODP tends to place the individual in the position of a consumer and no longer in the position of a citizen. This is, in fact, not unrelated to the more general place of the individual within the smart city (Kitchin and Cardhullo, 2019). A similar trend can also be found within the literature. As Hable et al. (2019) point out, "The distinction in users and consumers shows that citizens and users are clearly separate categories to consider. However, this separation is rarely made" (p. 24). Similarly, defined as a public service, the ODP limits the municipality to a role of data provider. The role of the municipal government within these initiatives and a clearer definition of the different target audiences would therefore need to be considered in order to redefine the objectives of ODPs. Finally, when the individual is thus positioned as a consumer, he or she is restricted to a short time frame that leaves no room for exchanging with other actors, which impedes the emergence of an eventual ecosystem. This conception of open data as a public service restricts and constrains the role of the city.

\subsection{A limited and constrained role for the city}

Designed as a service, the data platform limits the possibility for the team in charge of managing and feeding it to follow up on the products that may be created by the reuse of data and limits the connections that the team can make between reusers and other actors. This state of affairs affects two more specific elements. One, in the case of the City of Montréal, the objective of the team managing the platform is to release datasets. The City has also subsidized events and tried to partner with organizations to get this data reused by the public. But, would it be well advised to connect a reuser who has created an application with a start-up that might be interested in such an application? Hable et al. (2019) point out that "direct users of data not only have idealistic motivations, but chase rather practical and commercial motivations as well to engage in OGD [open government data] use" (p. 24). The added value created is therefore not politically neutral, especially if it pursues a commercial objective. By putting the management of open data and its accession in the hands of civil servants, it seems difficult, from a political point of view, to conceive that the public authorities would be capable of linking reusers with private or public companies (and to determine which ones to choose, and according to which criteria).

For Hable et al. (2019), for an ODP to fulfill its mission, the municipality must link infomediaries and citizens: the way most ODPs are currently designed, at least in Quebec, does not allow for the creation of such an ecosystem. We need to think about the design of this ecosystem and the place that each one holds. This touches on what Johnson (2019) calls the "disintermediation" between citizens and government, insofar as the private sector seems to be the more likely winner of these initiatives. This also goes back to the idea that it is appropriate to think about the audiences targeted by the release of data and more precisely, as Johnson points out, the added value created: "The challenge here is defining value for whom" (2019, p. 2869).

\subsection{Limited relevance of published datasets}

The interviews conducted and the identification of the available datasets raise questions about the usefulness of the published data. This usefulness is measured in terms of the objectives pursued: as is the case elsewhere, the objectives are greater democratic and economic ideals. While laudable, their pursuit should perhaps be seen more as a general framework within which action, especially political action, is taken.

Indeed, by linking data liberation to municipal policy objectives, in relation to the needs of the population and the territory, it is likely that an open data liberation initiative would gain in relevance and thus be able to reduce the criticisms that are currently found. However, the linkage of this initiative with local needs can only be achieved through the design of a political project supporting the initiative.

The City of Montréal has chosen to be open by default while responding to the various requests made of it. Nevertheless, insofar as the realization of the ODP is an institutional endeavor, it has not been driven by a demand from the population. By allowing citizens to request the opening of certain datasets, while organizing various events, the City is trying to respond to needs. However, it is clear that it is struggling to meet these needs. Moreover, these initiatives have not been the object of a democratic deliberation, be it with regard to the nature of these objectives or the means invested. Yet, consideration of both citizens and the territory from the start would most likely have contributed to meeting the objective of an ODP and thus avoid criticism of the relevance, or even the usefulness, of certain data. These limitations lead us to propose several avenues of research.

\section{RESEARCH AGENDA}

The Montreal experience has allowed us to provide the City with a set of recommendations, which we classified in three dimensions (feasible, desirable, ideal) according to the reality of the municipality. One of the ideal recommendations was to turn the ODP into a territorial development project, in order to 
discourage the notion that the ODP is a service. Conceived as a single service, it fails to produce networks of relationships where the production, circulation, use and valorization of open data take place. Similarly, this vision of an open data "service," while seemingly offering access to all, in fact only meets the needs of a minority: the infomediaries. ${ }^{3}$ It therefore fails to train or offer training tools to people who have no knowledge in the field. Generally speaking, and in keeping with a number of observations made about the smart city, the potential of open data, the very definition of what data is, needs to be explained to the general public. Only then can such an infrastructure become a first step toward a more participative infrastructure. These different reflections lead us to propose several avenues of research, particularly at the scale of municipalities.

Several research agendas have been formulated concerning open data. These agendas strive - and rightly so-to observe all the characteristics of the ODP ("1. Technologies; 2. Information; 3. Processes and Activities; 4. Products and Services; 5. Participants (including developers, data owners, and service developers); 6. Customers; 7. Environment (Lindman, Rossi and Tuunainen, 2013). We believe, however, that such an agenda needs to be contextualized in greater depth, particularly in light of the enthusiasm of municipalities to develop these infrastructures. This is all the more relevant as municipalities often have few means and competencies to act in this area. More specifically, it would be appropriate to look more closely at the political and territorial dimensions of open data initiatives and hence going beyond research on technical infrastructure and users, however relevant and necessary that may be. Several questions deserve to be asked.

\subsection{Why does a municipality choose to develop an ODP?}

As we have seen in our case study, the effort made to open up data remains modest, below what most of the users interviewed expect in terms of data offers or support. This raises the question of the municipalities' real motivations and the benefits that they and the population derive from those initiatives. The opening up of data has sometimes been driven by various needs and opportunities, or by aspects relating to trends, image and modernity, yet without the population perceiving and accepting it as real political progress. The difficulty of discerning the benefits of open data initiatives at the municipal level, and in particular of assessing the economic and social benefits, is an important research issue. It deserves more attention and should not be swept aside by the complexity of the task. This examination could take into account the question of the profitability of open information as well as that of the social value of building an ecosystem of territorial actors involved in the use of public open data.

\subsection{For whom are we creating such an infrastructure?}

Tied to the first question, surveys of open data users tend to emphasize that it is mainly infomediaries who organize information and facilitate an intersect of the supply and demand of available public information. This finding tempers the initial promises of open data activists for direct access to municipal information without intermediaries. As Pierre Johnson (2019) writes, we believe that the emergence of open data rather encourages the entry of new private intermediaries into the public

\footnotetext{
${ }^{3}$ As a reminder, we were unable to, in the context of our study, ascertain the number and profile of people who download
}

information processing chain through the development of applications (e.g., civic technologies). The role of these intermediaries - mostly private - in the production of narratives and meanings around open data by municipalities is questioned. This also raises the question of the nature of the added value that municipalities want to achieve by creating such an infrastructure. Is the added value derived from the exploitation of data intended solely for commercial purposes and to foster innovation (Kankanhalli, Zuiderwijk and Tayi, 2017)? Would it, then, be utopian to think that these data can increase city dwellers' capacity to act without necessarily having to go through a private service provider or an intermediary? If so, under what conditions? Within what kind of regulatory and legal frameworks?

6.3 How reliable and credible is this data? Is it not illusory to think that data produced and shared by the municipalities can contribute to better control and greater transparency of the organization that initiated this process?

The issues surrounding the "public" nature of the information disseminated through open data initiatives deserve to be examined in greater depth through the prism of the relationship of trust. In this sense, can open data contribute to improving citizens' trust in their political representatives? This is not a question of debating the influence of open data in the political debate but rather of understanding to what extent open data can also be, in certain circumstances, a tool for informing and disseminating municipal action. It would be relevant to look at the nature of the political issues that are highlighted (and those that are ignored) in the publication and dissemination of open data sets. These questions also lead us to wonder about the relationship of elected officials and city staff with open data. According to open data proponents, increasing political transparency is key to gaining social acceptance of these approaches among the population. However, we are not certain to what extent open data approaches are able to encourage greater transparency in municipal operations and decision-making. Pasquier and Villeneuve (2007) discuss a number of legal ways of impeding transparency, such as so-called laborious transparency, which consists of invoking "reasons related to a lack of resources and skills to justify restrictions, delays or any other problem limiting complete and rapid access to information" (p. 172), or so-called maximized transparency, which consists of making available to the public "an overabundance of information, thus preventing a person from extracting the relevant information in a rapid and efficient manner" (p. 173; our translations). Further research could be conducted to identify the nature of the transparency of municipal information obtained through open data platforms and, consequently, whether this transparency influences the trust that open data users have in the functioning and action of their municipality.

6.4 Is the portal, as a technological platform for managing and disseminating public information, sufficient to encourage the use of open data by the greatest number of people?

Municipalities approach open data based on their own institutional tradition. Internally, their work tends to revolve around the standardization of data catalogs. Therefore, they must be able to handle data access and distribution in an intelligible, usable and reusable format and be complemented by metadata. Does this top-down approach not ultimately lead to a

datasets without asking questions to the team that manages the portal. 
standardization of behavior and practices (Carmes and Noyer, 2013)? Is there another way to create the conditions for the emergence of other uses and user profiles? If so, are municipalities best placed to lead these processes and open up new forms of reflexivity in the production of knowledge and data use, as well as in enhancing public debates and learning on the part of the population?

\section{CONCLUSION}

What does the Montreal case study tell us about the debate on the discrepancy between the ideals and objectives of the open data movement and the limitations identified in the implementation of these initiatives in various municipalities?

Our study confirms that the conception of a data portal as a service limits its social, economic and political scope. This confirms the hypothesis that open data advocates too mechanically associate open data with reuse and, ultimately, with value. Under these conditions, it is difficult to achieve the objectives of transparency, citizen participation or economic development on a municipal scale. As Lobre and Lebraty (2012) predicted, the idealism of open data is gradually disappearing from the managerial practice of public information. While the first publications on open data generated a lot of enthusiasm and overblown promises, it is clear that the open data movement has not resulted in a radical transformation of local political life, nor of the way urban forms are designed or places are developed. Open data offers an additional, complementary source of data to citizens. For example, the existence of open datasets on the number of cyclists, the location of parks or the municipal budget has not replaced traditional surveys. At best, in our case, it saves time. The primary role of a municipality is to meet the daily needs of its population. Rather than focusing on the municipalities' ability to meet the objectives of open data, would we not be better served to understand what users actually do with open data, in order to identify how the opening of these datasets contributes to meeting their needs?

However, the open data movement in Montreal seems to have helped put the issue of digital data on the political agenda and to show the collaborative nature of data production, processing and analysis. A more global strategy is beginning to take shape in Montreal. A recent publication by an open data organization commissioned by the City of Montréal (Open North, 2021) heralds a turning point in the role and place the City wishes to assume within its digital data ecosystem. The report includes reflections on data governance and on the ways in which data, both open and non-open, could be collected, used, shared and controlled. The results of one part of the report show that the leaders of the City of Montréal do not have a common understanding of data governance, namely in terms of who should make decisions, how decisions should be made and how decision-makers should be held accountable for data management. In a sense, these report suggests a political reclaiming of the issue of municipal data. It will be interesting to observe how this new positioning influences the future of the ODP and the strategy implemented to facilitate the use of these resources.

\section{REFERENCES}

Abella, A., Ortiz-de-Urbina-Criado, M., De-Pablos-Heredero, D., 2019 : The process of open data publication and reuse.
Journal of the Association for Information Science and Technology, 70(3), 296-300. doi.org/10.1002/asi.24116.

Barbudo, C.F., 2015. El papel de la Smart City en el concepto de privacidad. Proceedings of the 11th International Conference on Internet, Law \& Politics. Universitat Oberta de Catalunya, Barcelona, 93-115.

Carmes, M., Noyer, J-M. (eds), 2013. Les débats $d u$ numérique. Nouvelle édition [en ligne]. Paris : Presses des Mines, available

$<$ http://books.openedition.org/pressesmines/1654>.

https://doi.org/10.4000/books.pressesmines.1654; 2021, June, 6.

Danneels, L., Viaene, S., Van den Bergh, J., 2017. Open data platforms: Discussing alternative knowledge epistemologies. Government Information Quarterly, 34(3), 365-78. https://doi.org/10.1016/j.giq.2017.08.007.

Davies, T., 2013. Open data barometer: 2013 global report. http://www.opendataresearch.org/dl/odb2013/Open-DataBarometer-2013-Global-Report.pdf.

Dickner, Nicolas, 2017. Comprendre et manipuler les données ouvertes de l'administration publique. La situation au Gouvernement du Québec et à la Ville de Montréal. Montréal: École de bibliothéconomie et des sciences de l'information. Master thesis.

Donker F., van Loenen, D., 2017. How to assess the success of the open data ecosystem? International Journal of Digital Earth, 10(3), 284-306, DOI: 10.1080/17538947.2016.1224938.

Economist (The), 2013. Show me the money. When transparency is the handmaiden to innovation.

http://www.economist.com/blogs/graphicdetail/2013/11/opendata- 0 .

Hable, J. 2019. Value Drivers and Inhibitors in Municipal Open Government Data Ecosystems: An in-depth analysis of stakeholder perceptions on values, barriers and success factors in open government data initiatives in Dutch municipalities. TU Delft Technology, Policy and Management. Master thesis.

Harrison, T.M., Pardo, T.A., Cook, M., 2012. Creating open government ecosystems: A research and development agenda. Future Internet, 4(4), 900-928. doi.org/10.3390/fi4040900.

Heimstädt, M., Saunderson, F., Heath, T., 2014. From toddler to teen: growth of an open data ecosystem. JeDEM-eJournal eDemocracy Open Gov. 6, 123-135.

DOI:10.29379/jedem.v6i2.330

Hivon, J., Titah, R., 2017. Conceptualizing citizen participation in open data use at the city level. Transforming Government: People, Process and Policy, 11(1), 99-118. DOI:10.1108/TG12-2015-0053

Immonen, A., M. Palviainen, E. Ovaska. 2014. Requirements of an Open Data Based Business Ecosystem. IEEE Access 2: 88- 103. https://doi.org/10.1109/ACCESS.2014.2302872.

Janssen, M., Y. Charalabidis, et A. Zuiderwijk. 2012. Benefits, Adoption Barriers and Myths of Open Data and Open Government, Information Systems Management, 29 (4), 258268, https://doi.org/10.1080/10580530.2012.716740 
Jetzek, T., 2015. The Sustainable Value of Open Government Data. Uncovering the Generative Mechanisms of Open Data Through a Mixed Methods Approach. Copenhagen Business School, Copenhagen.

Johnson, P., 2019. Disintermediating Government: The role of Open Data and Smart Structure. Proceedings of the $52^{\text {nd }}$ Hawaii International Conference on System Sciences, 2864-2871.

Kassen, M., 2018. Open data and its institutional ecosystems: A comparative cross-jurisdictional analysis of open data platforms. Canadian Public Administration, 61(1), 109-129.

Kitsios, F., Papachristos, N., Kamariotou, M., 2017. Business models for open data ecosystem: Challenges and motivations for entrepreneurship and innovation. Conference: 2017 IEEE 19th Conference on Business Informatics (CBI) (Vol. 1, pp. 398-407). IEEE.

Lassinantti, J., Ståhlbröst, A., Runardotter, M., 2019. Relevant social groups for open data use and engagement. Government Information Quarterly, 36 (1), 98-111. doi.org/10.1016/j.giq.2018.11.001.

Lindman, J., Kuk, G., 2015. From open access to open data markets: Increasing the subtractability of open data. 48th Hawail International Conference on System Sciences (pp. 1306-1313). IEEE.

Lobre, K., Lebraty, J.-F., 2012. L'open data : nouvelle pratique managériale risquée ? Gestion 2000, 29(4), 103-103. doi.org/10.3917/g2000.294.0103.

Máchová, R., Lněnička, M., 2017. Evaluating the quality of open data portals on the national level. Journal of Theoretical and Applied Electronic Commerce Research, 12(1), 21-41.

Magalhães, S., Galdino de, L., 2019. Toward the open government ecosystem: Connecting e-participation models and open government to analyze public policies. In Governance Models for Creating Public Value in Open Data Initiatives, edited by M. P. Rodríguez Bolívar, K. J. Bwalya and C. G. Reddick, 31, 85-102. Springer Nature, Cham. https://doi.org/10.1007/978-3-030-14446-3 4.

Martin, S., Turki, S., Renault, S., 2017. Open data ecosystems. International Conference on Electronic Government and the Information Systems Perspective (pp. 49-63). Springer Nature, Cham.

Neves, F. T., de Castro Neto, M., Aparicio, M., 2020. The impacts of open data initiatives on smart cities: A framework for evaluation and monitoring. Cities 106 (November): 102860. doi.org/10.1016/j.cities.2020.102860.

Noda, T., Yoshida, A., Honda, M., 2019. Economic effect by open data in local government of Japan. In ICT for a Better Life and a Better World, edited by Y. Baghdadi and A. Harfouche, 30, 165-73. Springer International Publishing, Cham. doi.org/10.1007/978-3-030-10737-6_11.

Open North. 2021. Les partenariats de données numériques : mettre les bases d'une gouvernance de données collaborative dans l'intérêt $d u \quad$ public. https://assets.ctfassets.net/e4wa7sgik5wa/62KQJwk6iQe6W6A AyNx4jF/ab490b34104169a68f0b2d5b8ef99a46/Digital data P artnerships Summary-FR.pdf
Ojo, A., Curry, E., Ahmadi Zeleti, F., 2015. A tale of open data innovations in five smart cities. 48th Hawaii International Conference on System Sciences, 2326-35. HI, USA: IEEE. doi.org/10.1109/HICSS.2015.280.

Open Knowledge Foundation, n.d., Why Open Data? https://opendatahandbook.org/guide/en/why-open-data/.

Paquienséguy, F., and V. Dymytrova., 2018. Open Data et Métropoles, Les Enjeux d'une Transformation à l'œuvre : Analyse Sémio-Pragmatique d'un Corpus de Portails Métropolitains. Questions de Communication, 34 (December): 209-28.

https://doi.org/10.4000/questionsdecommunication.15818.

Pasquier, M. and Villeneuve, J., 2007. Les entraves à la transparence documentaire. Établissement d'une typologie et analyse des comportements organisationnels conduisant à empêcher ou à restreindre l'accès à l'information. Revue Internationale des Sciences Administratives, 1(1), 163-179. https://doi.org/10.3917/risa.731.0163

Prieto, A. E., Mazon, J.N., Lozano-Tello, A., 2019. Framework for prioritization of open data publication: An application to smart cities. IEEE Transactions on Emerging Topics in Computing, 1-1. doi.org/10.1109/TETC.2019.2893016.

Ponte, D., 2015: Enabling an Open Data Ecosystem. ECIS 2015 Research-in-Progress Papers. Paper 55.

Rouquette, S., 2009. L'Analyse des sites internet. Une radiographiedu cyberesp@ce, Bruxelles, De Boeck.

Ruijer, E., Grimmelikhuijsen, S., van den Berg, J., Meijer, A., 2020. Open data work: Understanding open data usage from a practice lens. International Review of Administrative Sciences 86(1): 3-19. doi.org/10.1177/0020852317753068.

Sadiq, S., Indulska, M., 2017. Open data: Quality over quantity. International Journal of Information Management, 37(3), 150154. doi.org/10.1016/j.ijinfomgt.2017.01.003.

Shepherd, E., Bunn, J., Flinn, A., Lomas, E., Sexton, A., Brimble, S., Chorley, K., Harrison, E., Lowry, J., Page, J., 2019. Open government data: Critical information management perspectives. Records Management Journal 29(1/2), 152-67. doi.org/10.1108/RMJ-08-2018-0023.

Susha, I., Zuiderwijk, A., Janssen M. et al., 2015. Benchmarks for evaluating the progress of open data adoption: Usage, limitations, and lessons learned. Social Science Computer Review, 33(5), 613-630.

Sunlight Foundation, n.d., Tactical Data Engagement : Roadmap to Informed Communities. Website, https://communities.sunlightfoundation.com/methodology/. 2021, June, 6 .

Van Schalkwyk, F., Willmers, M., McNaughton, M., 2016. Viscous open data: The roles of intermediaries in an open data ecosystem. Information Technology for Development, 22(sup1), $68-83$.

Vetrò, A., Canova, L., Torchiano, M., Orozco Minotas, C., Iemma, R., Morando, F., 2016. Open data quality measurement framework: Definition and application to open government data. 
Government Information Quarterly, 33(2), 325-37. doi.org/10.1016/j.giq.2016.02.001.

Ville de Montréal, 2011. Étude publique du projet d'ouverture des données publiques à la Ville de Montréal. http://ville.montreal.qc.ca/pls/portal/docs/PAGE/COMMISSIO NS PERM V2 FR/MEDIA/DOCUMENTS/PV 20111115.PD F., 2021, June, 6 .

Ville de Montréal, 2015. Politique de données ouvertes. http://donnees.ville.montreal.qc.ca/portail/wpcontent/uploads/2015/10/Politique-dedonn $\%$ C $3 \%$ A9esouvertes.pdf. 2021, June, 6 .

Washington, A. 2019. Who do you think we are? The data publics in digital government policy. 52nd Hawaii International Conference on System Sciences, 3264-3272.

Wirtz, B. W., Weyerer, J.C., Rösch, M., 2019. Open government and citizen participation: An empirical analysis of citizen expectancy towards open government data. International Review of Administrative Sciences, 85(3), 566-86. doi.org/10.1177/0020852317719996.

The World Bank, 2013. New partnership seeks to bring benefits of open data to developing countries. http://www.worldbank.org/en/news/press-release/2013/09/18/ new-partnership-seeks-bring-benefits-open-data-developingcountries.
The World Bank, 2019. Open Data in 60 Seconds. http://opendatatoolkit.worldbank.org/fr/open-data-in-60seconds.html, 2021, June, 6.

Young, M. M., 2020: Implementation of digital-era governance: The case of open data in U.S. cities. Public Administration Review, 80(2): 305-15. doi.org/10.1111/puar.13156.

Zhu, X., Freeman, M.A., 2019. An evaluation of U.S. municipal open data portals: A user interaction framework. Journal of the Association for Information Science and Technology, 70(1), 27 37. doi.org/10.1002/asi.24081.

Zuiderwijk, A., Helbig, N., Gil-Garcia, J.R. Janssen, M., 2014. Special issue on innovation through open data - a review of the state-of-the-art and an emerging research agenda. Guest editors' introduction. Journal of Theoretical and Applied Electronic Commerce Research, 9(2), 1-2. doi.org/10.4067/S071818762014000200001.

Zuiderwijk, A., Janssen, M., Davis, C., 2014. Innovation with open data: Essential elements of open data ecosystems. Information Polity, 19(1, 2), 17-33.

Zuiderwijk, A, Shinde, R., Janssen, M., 2019. Investigating the attainment of open government data objectives: Is there a mismatch between objectives and results? International Review of Administrative Sciences, 85(4), 645-72. doi.org/10.1177/0020852317739115. 